\title{
Prion subcellular fractionation reveals infectivity spectrum, with a high titre-low PrPres level disparity
}

Victoria Lewis ${ }^{1,2}$, Cathryn L Haigh ${ }^{1,2}$, Colin L Masters ${ }^{2}$, Andrew F Hill ${ }^{2,3}$, Victoria A Lawson ${ }^{1,2}$ and Steven J Collins ${ }^{1,2^{*}}$

\begin{abstract}
Background: Prion disease transmission and pathogenesis are linked to misfolded, typically protease resistant $\left(\mathrm{PrP}^{\mathrm{res}}\right)$ conformers of the normal cellular prion protein $\left(\mathrm{PrP}^{\mathrm{C}}\right)$, with the former posited to be the principal constituent of the infectious 'prion'. Unexplained discrepancies observed between detectable Prpres and infectivity levels exemplify the complexity in deciphering the exact biophysical nature of prions and those host cell factors, if any, which contribute to transmission efficiency. In order to improve our understanding of these important issues, this study utilized a bioassay validated cell culture model of prion infection to investigate discordance between PrP ${ }^{\text {res }}$ levels and infectivity titres at a subcellular resolution.
\end{abstract}

Findings: Subcellular fractions enriched in lipid rafts or endoplasmic reticulum/mitochondrial marker proteins were equally highly efficient at prion transmission, despite lipid raft fractions containing up to eight times the levels of detectable PrPres. Brain homogenate infectivity was not differentially enhanced by subcellular fraction-specific cofactors, and proteinase $\mathrm{K}$ pre-treatment of selected fractions modestly, but equally reduced infectivity. Only lipid raft associated infectivity was enhanced by sonication.

Conclusions: This study authenticates a subcellular disparity in PrPres and infectivity levels, and eliminates simultaneous divergence of prion strains as the explanation for this phenomenon. On balance, the results align best with the concept that transmission efficiency is influenced more by intrinsic characteristics of the infectious prion, rather than cellular microenvironment conditions or absolute Prpres levels.

Keywords: Prion protein, Prion infectivity, Prion disease, Protease resistance, Subcellular localisation, Fractionation

\section{Background}

Prion diseases constitute a group of unique neurodegenerative disorders, which naturally afflict a number of mammalian species including humans. Although our understanding remains incomplete, considerable evidence supports the "protein-only" hypothesis, which purports that the agent ("prion") responsible for both transmission and consequent pathogenesis is predominantly composed of misfolded conformers of the normal cellular prion protein $\operatorname{PrP}^{\mathrm{C}}[1]$. Additional discriminating features of the aberrant prion protein include increased $\beta$-sheet content $[2,3]$, reduced solubility and

\footnotetext{
* Correspondence: stevenjc@unimelb.edu.au

'Department of Pathology, The University of Melbourne, Parkville, VIC 3010, Australia

Full list of author information is available at the end of the article
}

increased tendency to aggregate, and typically heightened protease resistance [4-6]. Due to the characteristic protease resistant core, limited proteolysis with proteinase $\mathrm{K}(\mathrm{PK})$ truncates the $\mathrm{N}$-terminus of the misfolded protein, producing $\operatorname{Pr} \mathrm{P}^{\text {res }}$, whilst $\operatorname{PrP}^{\mathrm{C}}$ is completely degraded, allowing a convenient biochemical differentiation of these two prion protein isoforms.

An intriguing but somewhat perplexing aspect of prion biology is the several instances in transmission studies, encompassing many prion strains, where infectivity titres and $\mathrm{PrP}^{\mathrm{res}}$ levels (as detected by biochemical assessment of inocula) do not faithfully correlate. Illustrating this are pre-clinical prion infections after low dose transmissions [7], BSE infectivity in tongue and nasal mucosa [8] and slowly sedimenting high titres of infectivity separated from $\operatorname{PrP}^{\text {res }}$ in 'fast' prion strains [9]. Further examples

\section{Biomed Central}


have occurred during cross species transmissions including intracerebral inoculation of hamster prions to mice [10], primary passage of bovine prions to rodents $[11,12]$, scrapie prions peripherally introduced into mice [13] and transmission of three distinct prion strains (human, hamster scrapie, murine scrapie) into transgenic mice expressing the murine equivalent of a human prion protein gene mutation [14]. In addition, $\mathrm{PrP}^{\mathrm{res}}$ generated through protein misfolding cyclic amplification (PMCA) evinces a longer incubation period (indicative of a lower titre) despite western blot detection levels equivalent to those observed in the original seeding inoculum [15]. This PMCA study suggests that a component within the original inoculum, which perhaps does not propagate or amplify as well as $\mathrm{PrP}^{\mathrm{res}}$, may contribute to the more efficient transmission. Although $\mathrm{PrP}^{\mathrm{res}}$ is inextricably linked to prion infectivity, these numerous examples clearly illustrate the poorly understood complexities of this relationship.

The precise cellular location of $\operatorname{PrP}^{\mathrm{C}}$ misfolding and conversion also remains speculative (reviewed in [16]), as does the contribution of cellular co-factors to conversion efficiency, although the participation of a species-specific protein [17-19], or negatively charged macromolecules such as nucleic acids [20-24] and glycosaminoglycans [25-29] has been posited. In contrast, evidence exists correlating the efficiency of prion propagation and transmission with the size of prion multimers serving as templates for conversion [30,31]. Acknowledging the aforementioned uncertainties, the current study investigated whether such observed disparities between infectivity titres and $\mathrm{PrP}^{\mathrm{res}}$ levels could be resolved to a subcellular level and thereby provide a useful model for insights into the molecular basis of this observation. To address this aim, we utilized fractionation of MoRK13 cells infected with M1000 prions to explore the contributions of subcellular co-factors and cognate prion protein species to the efficiency of transmission.

\section{Results}

Prion protein conformers reside predominantly in lipid rafts in MoRK13 and MoRK13-inf cells

Characterisation of the MoRK13-M1000 prion infection model (MoRK13-inf) determined that per detectable 'PrP ${ }^{\text {res }}$ unit', MoRK13-inf cell lysate was approximately 90 times more efficient than crude M1000 brain homogenate at prion transmission to recipient MoRK13 (Additional file 1: Figure S1). This finding, perhaps an example of strain adaptation into a rabbit cell line, highlighted a discrepancy between $\mathrm{PrP}^{\mathrm{res}}$ and infectivity levels, and indicated that MoRK13-inf cells may be an appropriate model to study this phenomenon. PrP isoforms have been shown to localise to various subcellular environments, including those of the secretory and endocytic pathways, and at the cell surface [32-34]. Figure 1 shows the localisation of organelle markers Bcl-2 (mitochondria; MT), Bip (endoplasmic reticulum; ER), and EEA1 (early endosome; EE) in the MoRK13 cells. As expected, the lipid raft marker Flotillin 1 was enriched within fractions at the buoyant end of the gradient, consistent with the high cholesterol:protein ratio resulting in a significantly lower density of lipid rafts compared to other solubilised membrane proteins [35]. This was confirmed by dot blot analysis of the lipid raft marker $G_{1}$, detected by the cholera toxin subunit B (CTB). Figure 1 also indicates that the subcellular localisation of $\operatorname{PrP}^{C}$ in MoRK13, and total $\operatorname{PrP}\left(\operatorname{PrP}^{C}\right.$ and $\operatorname{PrP}^{\text {res }}$, indistinguishable from each other under the conditions of these western blots) in MoRK13-inf is predominantly in the buoyant, lipid raft fractions. There were no substantial differences in organelle or membrane markers or PrP localisation when comparing the MoRK13 and MoRK13-inf cells, and also comparing vector-only transfected RK13 (vecRK13), GT1-7H and GT1-7H-inf cells (Additional file 2: Figure S2); therefore over-expression of $\mathrm{PrP}^{\mathrm{C}}$, prion infection and cell line origin (neuronal/non-neuronal/murine/rabbit) do not appear to alter localisations, or create artefacts in this system of subcellular fractionation. Previous reports indicate $\mathrm{PrP}^{\mathrm{res}}$ is also localised in lipid rafts [36]. Figure 2A shows the localisation of MoRK13-inf $\mathrm{PrP}^{\text {res }}$ to be principally in lipid raft fractions, with a similar distribution to total PrP (Figure 1) as determined by both western blot and dot blot. Quantification of relative $\mathrm{PrP}^{\mathrm{res}}$ levels (Figure 2B) highlights that the lipid raft enriched fractions contain up to eight times the detectable $\operatorname{PrP}^{\text {res }}$ levels than the ER/MT marker enriched fractions (eg compare fractions \#3 and \#8). By way of comparison to the original prion strain, Nycodenz gradient distribution of PrP isoforms and marker proteins from M1000 brain, homogenised in a comparative manner, was also similar to that observed in cell lysates (Additional file 3: Figure S3).

\section{High levels of prion infectivity are present in lipid raft} and ER/MT marker enriched fractions of MoRK13-inf cells In order to determine whether detectable subcellular $\mathrm{PrP}^{\mathrm{res}}$ levels correlate with infectivity, an in vitro cell culture transmission study was carried out of equivalent volumes of fractions obtained after density gradient flotation assays of MoRK13-inf cell lysate using the highly susceptible MoRK13 as recipient cells. Levels of PrP $\mathrm{P}^{\text {res }}$ produced by recipient cells after exposure to fractions were quantified and used as a surrogate indicator of relative infectivity titres contained within the subcellular fractions. The representative cell blot and quantification (Figure 3A, B) clearly show that infectivity was contained within all fractions derived from MoRK13-inf cells, albeit to varying degrees. The EE enriched fractions (predominantly \#9 and \#10) contained considerably less infectivity compared with the lipid raft 


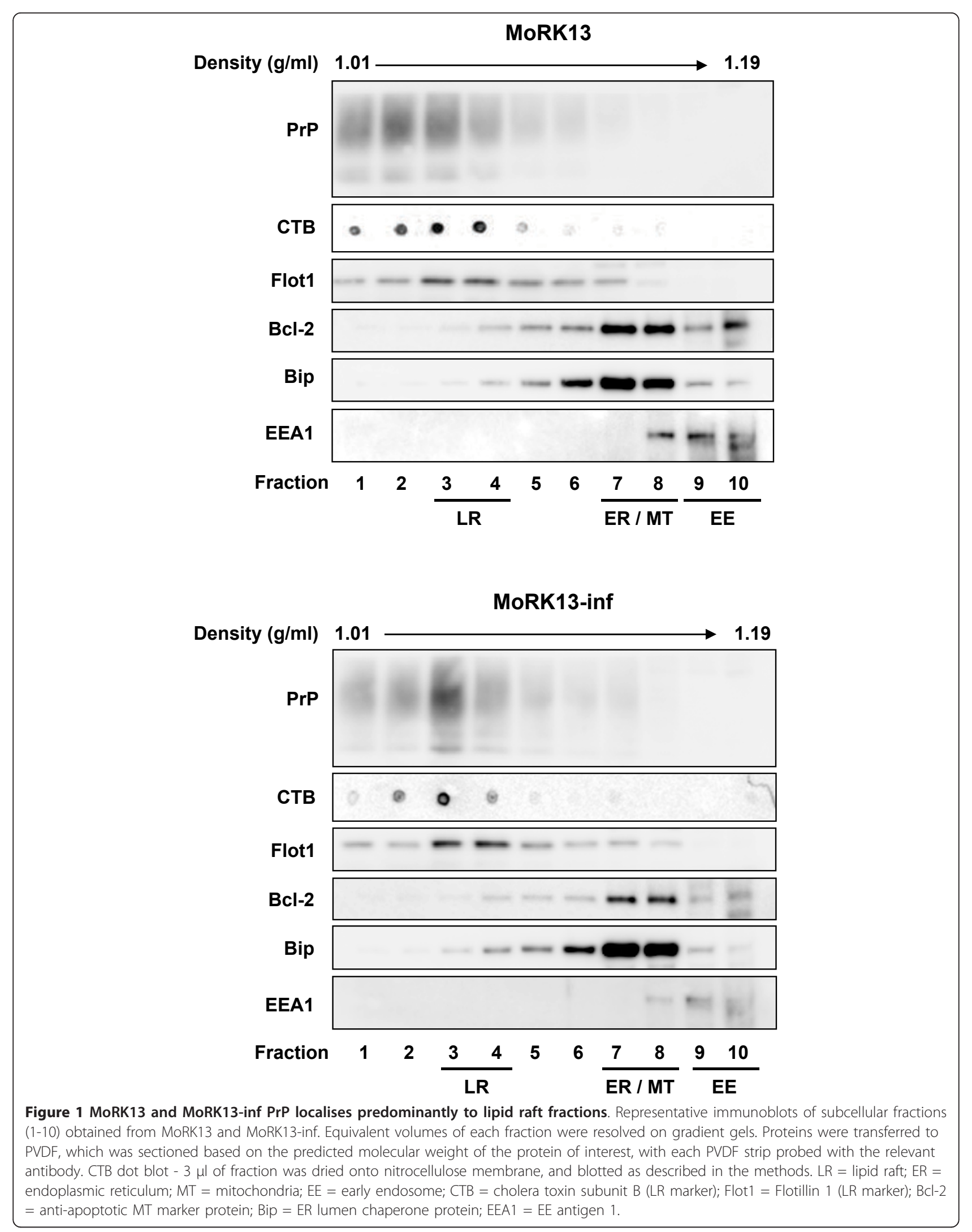



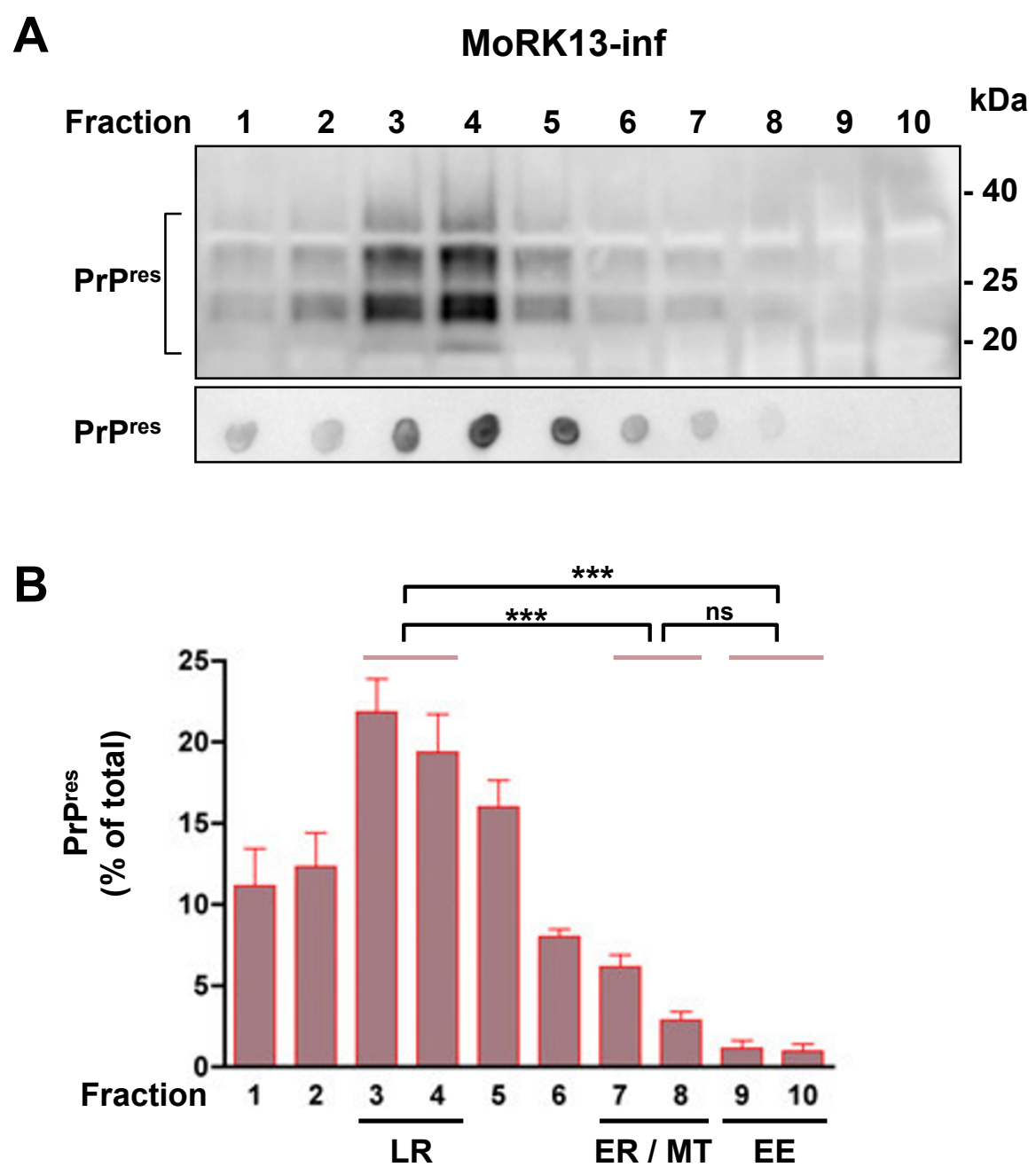

Figure 2 PrPres $^{\text {res }}$ is enriched in lipid raft fractions of MoRK13-inf cells. (A) Equivalent volumes of PK treated MoRK13-inf fractions resolved on 10-20\% Tris-glycine SDS PAGE and immunoblotted (top panel), and representative fraction PrPres dot blot (bottom panel). (B) Quantification of PrPres from dot blots of six separate cellular fractionations. Fractions enriched in lipid raft (LR), endoplasmic reticulum (ER), mitochondrial (MT) and early endosome (EE) marker proteins are highlighted. Comparison of relative PrPres levels by one way ANOVA; ${ }^{* *} p<0.001, n s=$ not significant.

enriched fractions (predominantly \#3 and \#4), and the ER and MT marker enriched fractions (predominantly $\# 7$ and \#8), although the comparison of fraction \#7 and fraction \#9 did not reach significance. Interestingly, there was no significant difference in the amount of infectivity contained within the lipid raft enriched fractions (\#3 and \#4), and the ER and MT marker enriched fractions (\#7 and \#8). As shown in Figure 3A, fractions were also diluted in a $1 / 2 \log$ series, to ensure there was no limiting sensitivity of the in vitro assay truncating the upper end of the dynamic range. Importantly, neat fractions that elicited the highest production of $\operatorname{PrP}^{\text {res }}$ by recipient MoRK13 cells (for example fractions \#4 and \#8), were infectious to the same dilutions (1:100), thereby validating the use of $\operatorname{Pr}^{\text {res }}$ produced by recipient cells as a measure of relative infectivity contained within fractions.
ER and MT marker enriched fractions show disparity between PrP ${ }^{\text {res }}$ levels and infectivity titres in vitro and in vivo

Correlation of the percentage of $\mathrm{PrP}^{\mathrm{res}}$ present in each fraction with the level of in vitro infectivity produced by each fraction (Figure 4A) revealed a discrepancy in the ER/MT enriched fractions. The relative levels of $\mathrm{PrP}^{\mathrm{res}}$ present in the lipid raft enriched fractions (\#3 \& \#4) and the early endosome enriched fractions (\#9 and \#10) correspond with the relative levels of $\mathrm{PrP}^{\text {res }}$ produced by the recipient MoRK13 cells. In contrast, the ER/MT enriched fractions (\#7 and \#8) that display low detectable PrP $P^{\text {res }}$ levels, contained high infectivity levels similar to the lipid raft enriched fractions, with the discrepancy at fraction \#8 highly significant ( $<0.001$; two way ANOVA). Therefore, there was a reproducible and significant 


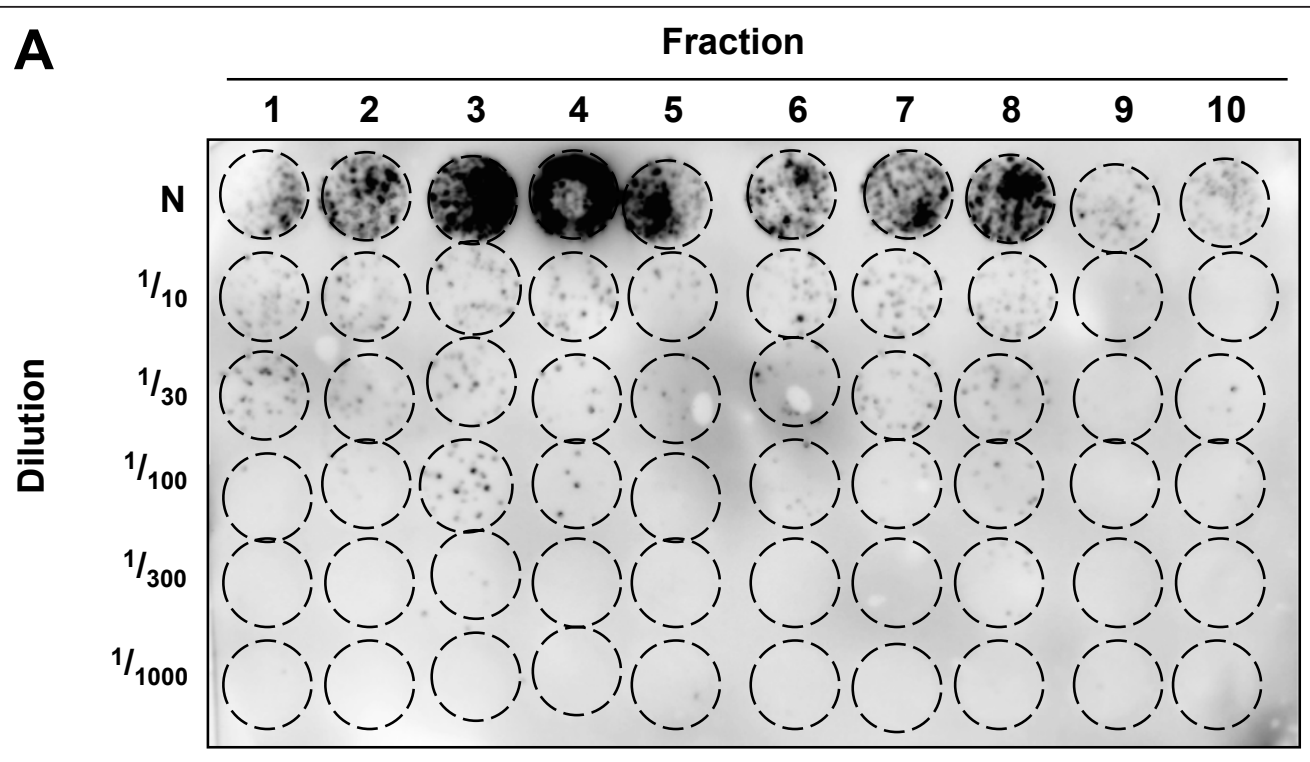

B

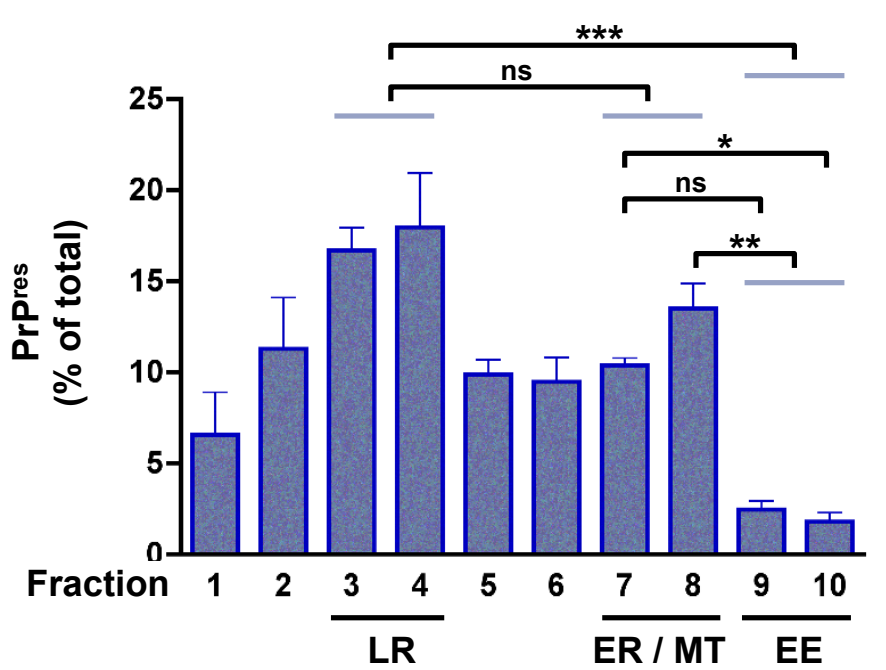

Figure 3 All MoRK13-inf fractions contain infectivity. (A) Representative cell blot showing PrPres levels produced by recipient MoRK13 cells at passage 4 (P4) post-exposure to equal volumes of each fraction at the 'neat' dilution ( $N$ ) or further serially diluted (1/10-1/1000). (B)

Quantification of infectivity from three independent MoRK13-inf fractionations $(n=3)$; fractions enriched in lipid raft (LR), endoplasmic reticulum (ER), mitochondrial (MT) and early endosome (EE) marker proteins are highlighted. Statistical analysis by one way ANOVA; only the statistical findings for relevant comparisons are indicated: ${ }^{* *} p<0.001,{ }^{* *} p<0.001,{ }^{*} p<0.05$, ns $=$ not significant.

divergence between $\operatorname{PrP}^{\mathrm{res}}$ and infectivity levels within ER/MT marker enriched fractions.

To confirm genuine prion infectivity, selected fractions were bioassayed in Tga20 $\mathrm{PrP}^{\mathrm{C}}$ over-expressing mice. The fractions were chosen to provide a range of $\operatorname{PrP}^{\text {res }}$ and infectivity level combinations; ie high $\operatorname{PrP}^{\text {res }}$ and infectivity levels (fraction \#4), low $\operatorname{Pr}^{\text {res }}$ and infectivity levels (fraction \#10), and low $\operatorname{PrP}^{\text {res }}$ but high infectivity levels (fraction \#8). Controls included inoculating mice with whole cell lysate from naive MoRK13 and MoRK13-inf cells, as well as M1000 brain homogenate, in order to make comparisons with the original prion strain. Figure 4B depicts the incubation periods for the selected fractions and control mice. Mice exposed to uninfected MoRK13 cell lysate were symptom free at 245 days post-inoculation. Mice inoculated with $0.01 \%$ M1000 brain homogenate had a significantly shorter incubation period than mice inoculated with MoRK13-inf whole cell lysate. Importantly, concordant with the in vitro cell culture transmissions, mice inoculated with fractions $\# 4$ and $\# 8$ had indistinguishable 


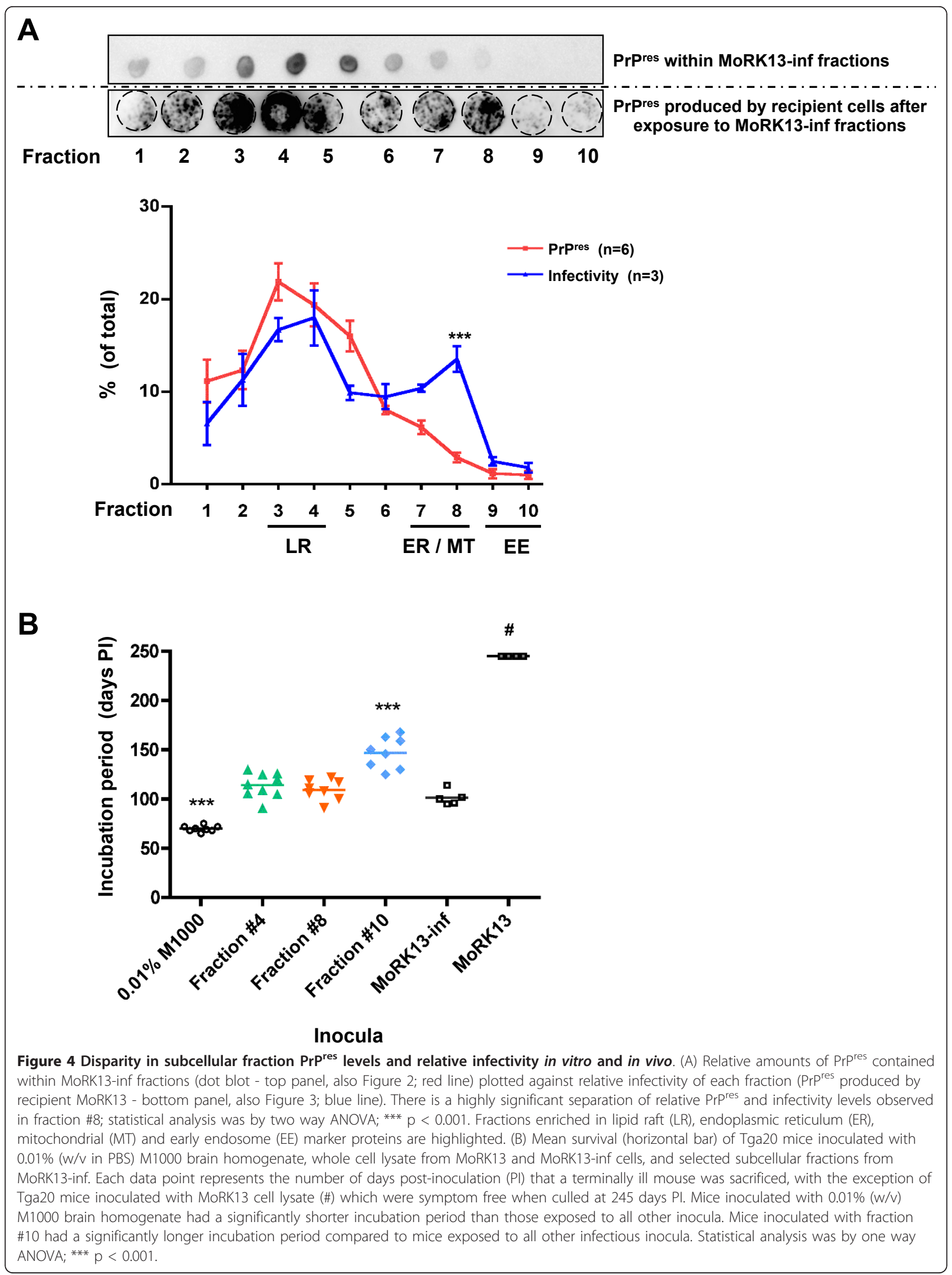


incubation periods, despite the significantly different $\operatorname{PrP}^{\text {res }}$ levels contained within these fractions. Mice inoculated with fraction \#10 had significantly longer incubation periods than mice infected with the other two fractions, again concordant with the relative infectivity levels determined by the cell culture transmissions. For illustrative purposes, this 35 day extension in incubation period approximates a $3 \mathrm{log}$ reduction of infectious titre when modelled on a time interval assay developed in Tga20 mice inoculated with M1000 brain homogenate derived prions (Additional file 4: Figure S4). In summary, the in vivo findings faithfully recapitulate and validate the MoRK13 in vitro model.

\section{Infectious prions from different subcellular fractions do not induce unique disease in vivo}

Neuropathologically, prion diseases are characterised by the presence of neuronal loss, spongiform change, proliferation of astrocytes and extracellular PrP deposits [37]. Further, for different prion strains the topographical distribution of neuropathological changes is distinctive, creating characteristic lesion profiles $[38,39]$. All diseased mice displayed symptoms typical of M1000 prion infection and brains were harvested to assess neuropathological changes. As expected, control mice inoculated with MoRK13 whole cell lysate showed no neuropathological abnormalities (Additional file 5: Figure S5). Figure 5 displays the quantification of the neuropathological features mentioned above within different brain regions, clearly indicating that each inoculum produced very similar lesion profiles (for representative photomicrographs of the histological and immunohistochemical findings see Additional file 5: Figure S5). This distribution pattern of the pathological features, with predominant involvement of the thalamus, midbrain and pons, and minimal involvement of the cerebellum is consistent with previous observations of the M1000 strain [40,41]. The only significant difference detected in lesion profiles was between MoRK13-inf whole cell lysate and fraction \#10 inocula, with the former having significantly more reactive astrocytes in the occipital cortical region. The explanation for this is uncertain, but may suggest an additive effect of the individual fractions, which contribute to the whole-cell lysate profile. Different prion strains often have distinctive $\mathrm{PrP}^{\text {res }}$ glycoform ratios and mobilities on western blot analysis [42-46]. To further evaluate the possibility of different MoRK13-inf subcellular fractions associating with distinct prion strains, the brain $\mathrm{PrP}^{\text {res }}$ profiles from Tga20 mice inoculated with selected fractions were examined by western blot. Similar to the lesion profiling, there were no significant differences in $\mathrm{PrP}^{\text {res }}$ patterns when comparing MoRK13-inf whole cell lysate with each of the selected fractions, in keeping with them all being the same prion strain (Additional file 6: Figure S6).
The efficiency of M1000 prion transmission is not enhanced by exogenous fraction specific co-factors in vitro or in vivo

In order to explore whether subcellular fraction specific co-factors might contribute to the observed transmission efficiency spectrum, M1000 brain homogenate was spiked into fractions derived from uninfected MoRK13 or vecRK13 cells, prior to use as inocula in vitro. Figure 6A shows that even at the lowest dilutions of M1000 in MoRK13 fractions, $\operatorname{PrP}^{\text {res }}$ was produced by recipient MoRK13 cells. However, quantification (Figure 6B) shows there were no significant differences in amounts of $\mathrm{PrP}^{\text {res }}$ produced when comparing the various MoRK13 subcellular fraction diluents. Notably, there was a general trend for MoRK13 subcellular fractions to enhance M1000 transmission efficiency to MoRK13 cells compared to lysis buffer alone. A similar result was observed using fractions obtained from vecRK13 cells (Additional file 7: Figure $\mathrm{S7}$ ), suggesting this trend is not $\operatorname{PrP}^{\mathrm{C}}$ specific or dependent.

To further evaluate the possible contribution of cellular co-factors on the efficiency of prion infection, M1000 brain homogenate was diluted in PBS or selected subcellular fractions from uninfected MoRK13 cells (fractions \#4, \#8 and \#10), and bioassayed in Tga20 indicator mice. M1000 was also diluted in 'empty' Nycodenz fractions (\#4, \#8 and \#10), in order to control for any affect the Nycodenz gradient material itself may have on incubation period or the neuropathology. Neither the exogenous cellular co-factors in the selected fractions, nor Nycodenz alone, had any significant affect on the incubation time (Figure 6C) or overtly affected the neuropathology (Addtional file 8: Figure S8) of M1000 in Tga20 mice.

\section{Discrepancies between PrP ${ }^{\text {res }}$ and transmission efficiency are not due to protease-sensitive prions, and only in lipid raft enriched fractions is infectivity enhanced by sonication}

There is experimental evidence that some disease associated [47-50], and synthetic [51] prions, may be protease sensitive. To test whether the infectious prions within the MoRK13-inf fractions may differentially contain significant amounts of protease sensitive species, selected fractions were digested mildly with PK prior to using them as a source of infectivity. There were no significant differences in $\mathrm{PrP}^{\mathrm{res}}$ levels produced by MoRK13 infected with PK digested fractions \#4, \#8 or \#10 compared to cells infected with the untreated fraction counterpart (Figure 7A, B). However there was a modest general trend towards reduced $\mathrm{PrP}^{\mathrm{res}}$ production by recipient cells after PK treatment of each fraction inoculum.

Evidence suggests misfolded prion protein aggregate size correlates with efficiency of conversion or prion 


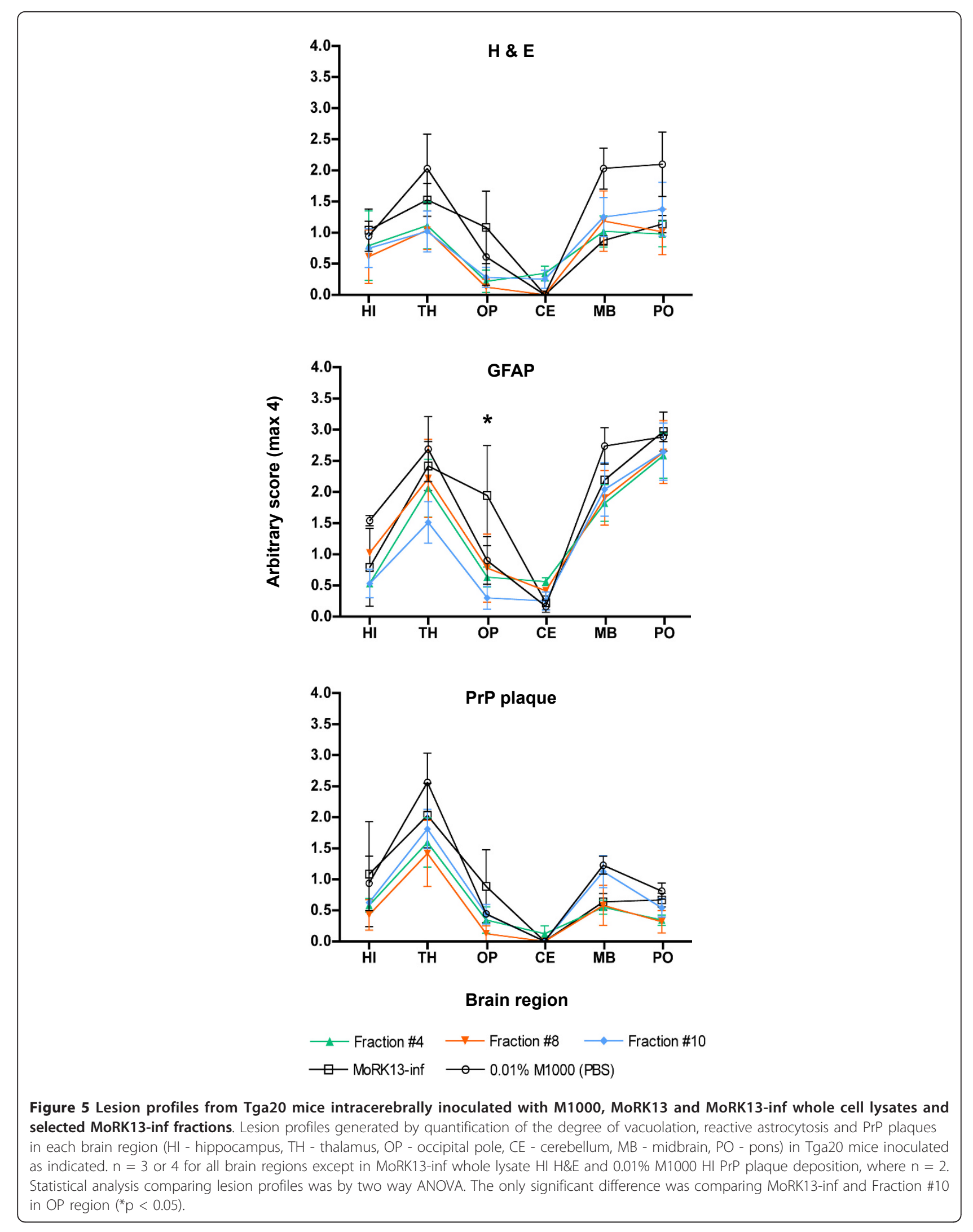




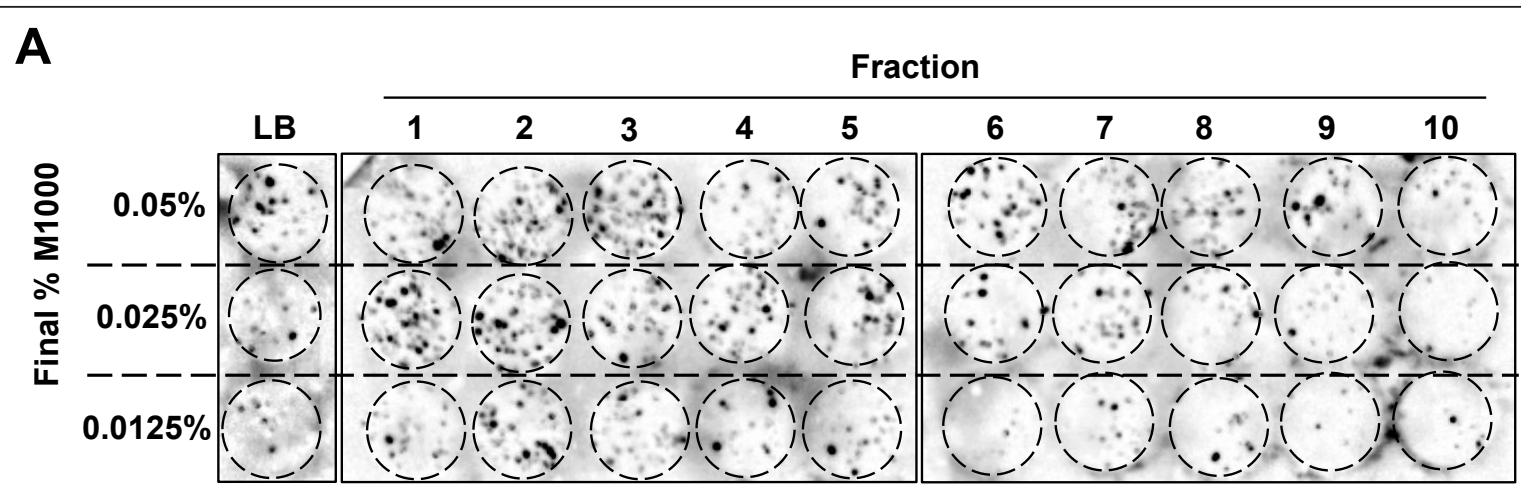

B

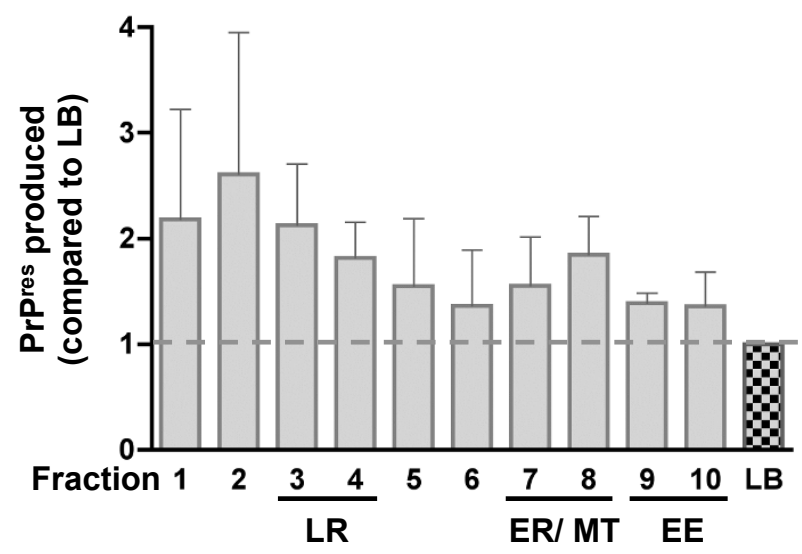

C

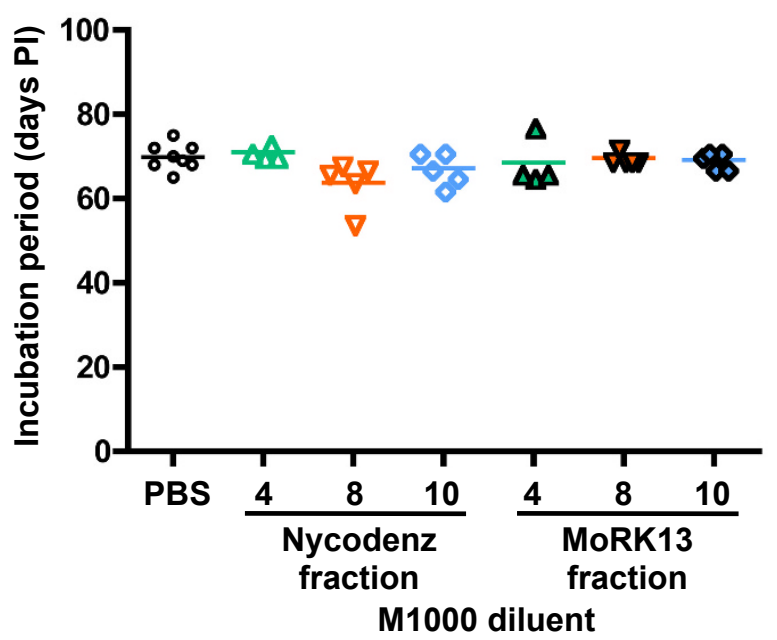

Figure 6 Exogenous cellular co-factors do not modify the efficiency of M1000 infection in vitro or in vivo. (A) Representative cell blot showing PrPres levels produced by recipient MoRK13 cells exposed to M1000 brain homogenate diluted to three different final concentrations (as indicated) with either 1:4 lysis buffer (LB):medium or 1:4 MoRK13 fraction:medium mix. (B) Quantification of PrPres produced by MoRK13 cells exposed to M1000 brain homogenate diluted in subcellular fraction relative to the equivalent \% M1000 brain homogenate diluted in lysis buffer; data is from M1000 spiked into three independent fractionations of MoRK13. For quantification purposes, the three different \% M1000 spikes into the same MoRK13 fractionated lysate were considered a triplicate of the same experiment. Fractions enriched in lipid raft (LR), endoplasmic reticulum (ER), mitochondrial (MT) and early endosome (EE) marker proteins are highlighted. Analysis of relative levels of PrPres produced after infection was by one-way ANOVA with Tukey's multiple comparison test; no significant differences found comparing subcellular fractions. (C) Survival of Tga20 mice inoculated with M1000 brain homogenate diluted to $0.01 \%$ with either PBS, selected fractions from an empty Nycodenz gradient, or selected subcellular fractions from MoRK13 cells. Each data point represents the number of days post-inoculation (PI) which mice were sacrificed because of terminal prion disease. Statistical analysis was by one way ANOVA, with no significant differences in survival seen between any inocula. 

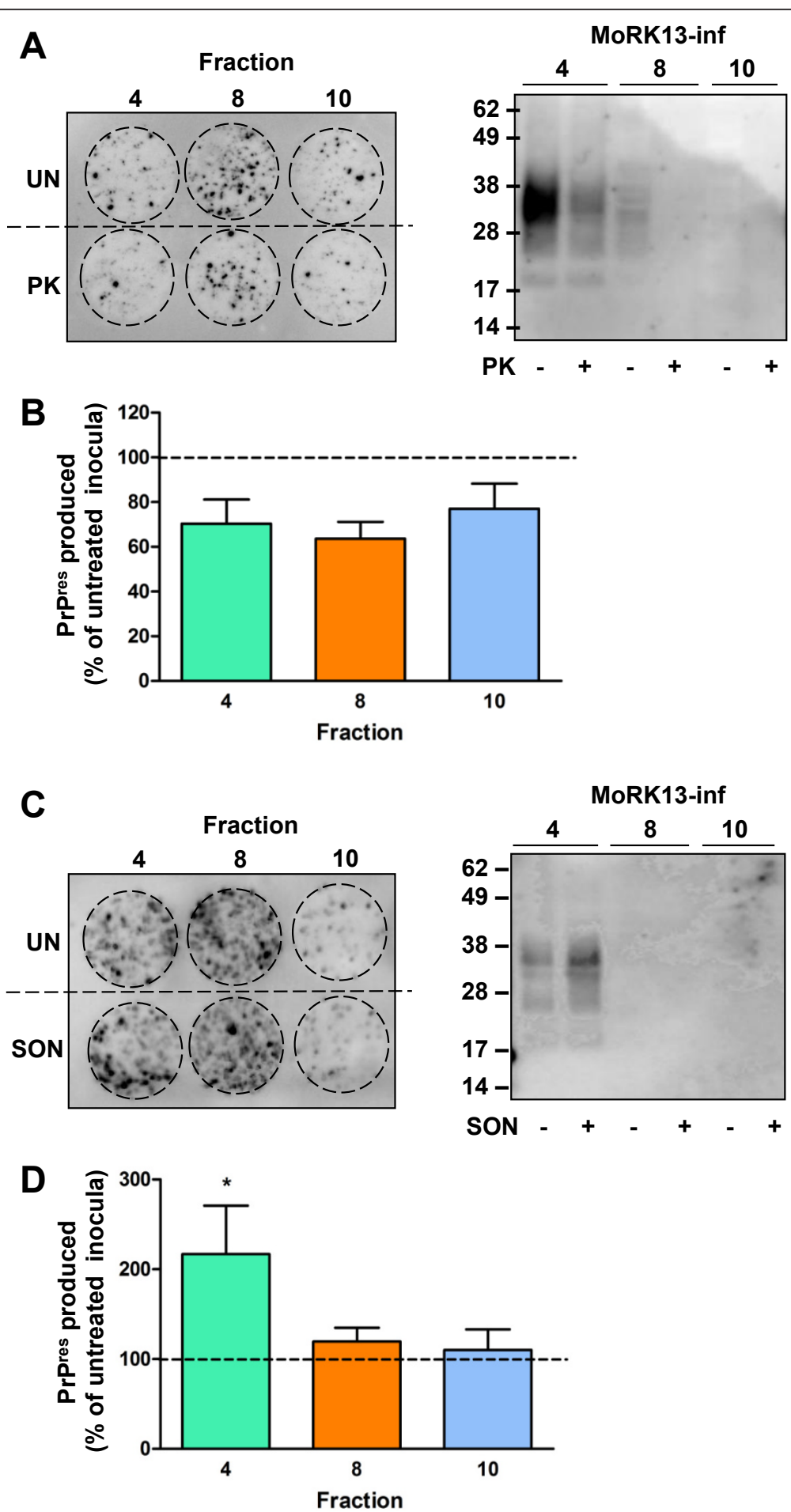

Figure 7 Sonication but not PK treatment alters efficiency of in vitro infection with fraction \#4 only. (A) Representative cell blot (left panel) of PrPres produced by MoRK13 cells exposed to selected MoRK13-inf fractions which were PK digested (PK) or left untreated (UN) and western blot (right panel) of MoRK13-inf inocula before and after PK treatment. (B) Quantification of cell blot PrPres levels ( $n=3$ independent experiments), with PrPres produced after infection with PK treated inocula expressed relative to untreated MoRK13-inf fraction inocula. (C) Representative cell blot (left panel) of PrPres produced by MoRK13 cells exposed to selected MoRK13-inf fractions which were sonicated (SON) or left untreated (UN) and western blot (right panel) of MoRK13-inf fraction inocula before and after sonication. (D) Quantification of cell blot PrPres levels expressed relative to untreated MoRK13-inf fraction inocula ( $n=3$ independent experiments). Note, levels of total PrP in fractions \#8 and $\# 10$ are at or below the limits of detection by standard immunoblotting. Comparison of relative PrPres levels by one way ANOVA and Dunnett's post-test for specific comparisons to a control (ie untreated fraction) found no significant differences in any PK treated inocula, and only sonicated MoRK13-inf fraction \#4 was significantly different compared to its untreated control, ${ }^{*} \mathrm{p}<0.05$. 
infection [30,31]. As a consequence, in vitro conversion assays such as PMCA may be most efficient when incorporating sonication steps $[52,53]$. To assess this possibility, selected fractions (\#4, \#8 and \#10) were subjected to sonication (equivalent to one 'round' of PMCA) prior to using them as a source of infectivity in the MoRK13 cell culture model. As demonstrated by the representative cell blot in Figure 7C, quantified in Figure 7D, only subcellular fraction \#4 had significantly increased levels of infectivity compared to its untreated fraction.

\section{Discussion}

The protein-only hypothesis states that misfolded conformers of the normal cellular prion protein are the principal component of the agent responsible for transmitting prion disease [1]. However, previously observed examples of high infectivity titres associated with very low or undetectable $\operatorname{Pr} \mathrm{P}^{\text {res }}$, the commonly utilized surrogate prion marker, suggest a poorly understood spectrum of infectious prions. Assessing the subcellular environment of the most infectious prions may provide information about optimal $\mathrm{pH}$ or metal content conditions, implicate membrane domains, or subcellular co-factors involved in localisation of highly efficient prions. Investigation of the subcellular distribution of prion infectivity and corresponding $\operatorname{PrP}^{\text {res }}$ levels has been previously reported, albeit to a limited extent. However, absent in prior studies were attempts to explore what determines the intracellular topographical diversity of prions or the molecular basis of any observed discrepancies in $\operatorname{PrP}^{\text {res }}$ and infectivity levels.

The present study clearly indicates that not all prion infectivity is associated with lipid rafts, although the significance of the lipid raft microenvironment in $\mathrm{PrP}^{\mathrm{C}}$ misfolding and prion conversion is yet to be resolved, with experimental evidence both for and against lipid raft localisation as an optimal site (reviewed in [16]). In complete agreement with the protein-only hypothesis, lipid raft and EE marker associated infectivity and $\mathrm{PrP}^{\mathrm{res}}$ were shown to correlate in the MoRK13-inf model. In contrast however, ER/MT marker enriched fractions contained much greater infectivity when reported to relative PrP ${ }^{\text {res }}$ content. That lipid raft and ER/MT enriched fractions contain the same infectivity levels indicates some biological redundancy or relative inefficiency of the lipid raft localised prions, and/or higher efficiency of ER/MT localised prions, prompting further investigation.

Cell-free conversion studies have shown there is a role for cellular co-factors, such as nucleic acid or other polyanionic molecules, in the efficiency of prion conversion and propagation $[21-23,29,54]$. Perhaps militating against a prominent role of specific co-factors contributing to the transmission efficiency of the MoRK13-inf subcellular fractions, infectivity of brain derived M1000 prions was not significantly differentially enhanced by dilution across various subcellular fractions. However, an explanation for this result is that the transmissible prions within M1000 brain homogenate were already largely in an optimal state, pre-formed and associated with the necessary cofactors required for infection. Therefore additional exogenous co-factors supplied via the MoRK13 or vecRK13 subcellular fractions were somewhat superfluous. Alternatively, the fractionation procedure itself may have inactivated any critical co-factors, such that they were not able to significantly enhance the infectivity of M1000 brain homogenate. In fact, there was a clear trend for increased $\mathrm{PrP}^{\mathrm{res}}$ propagation by recipient cells after infection with M1000 diluted in subcellular fractions compared to the lysis buffer only control, independent of whether the fractions contained $\operatorname{PrP}^{C}$. This may indicate that incompletely defined but relatively ubiquitous 'cellular co-factors' contribute to the efficiency of in vitro prion transmission, which would be consistent with previous studies.

Numerous prion strains exist, evident in both naturally occurring human $[55,56]$ and animal $[38,57-60]$ prion disease, as well as those adapted to laboratory based animal models. One hypothesis for what determines different strains is the tertiary structure of the prion conformer, possibly affected by metals, co-factors or binding partners [61]. It is also believed that prions may adopt various stable tertiary conformations, and there is evidence of simultaneous propagation of more than one prion strain within the brain $[55,62,63]$. Furthermore, super-infection experiments indicate that the more infectious strain will predominate and determine disease expression [64-66]. Prion strains can be classified by their distinctive neuropathological lesion profiles, incubation periods, $\mathrm{PrP}^{\mathrm{res}}$ glycosylation patterns and electrophoretic mobilities $[39,42,43,46]$. As RK13 cells are capable of supporting and maintaining propagation of many prion strains [67], and each fraction represented different subcellular localisations and potential binding partners, we explored the possibility that MoRK13-inf fractions contained structurally distinct prions of variable transmission efficiency. However histological and western blot analyses failed to detect any evidence of a subcellular divergence of prion strains, strongly militating against this as the explanation for the apparent increased relative infectivity in the ER/MT marker enriched fractions.

Previous experiments have shown that $\mathrm{PrP}^{\text {res }}$ aggregate size affects the efficiency of conversion and prion infection, perhaps through effects on optimising the available templating surface $[30,31]$, with oligomers of five or fewer $\mathrm{PrP}^{\text {res }}$ molecules and larger fibrillar aggregates of $\mathrm{PrP}^{\text {res }}$ far less efficient than non-fibrillar particles of 14-28 molecules [30]. There is also experimental evidence that a proportion of disease associated prions are protease sensitive [47-49], which may form low molecular weight aggregates $[47,49]$. 
The results presented herein show that only a minor proportion of prion infectivity within MoRK13-inf fractions is protease sensitive, and is unlikely to account for the disconnect observed between $\operatorname{Pr} P^{\text {res }}$ levels and infectivity in the ER/MT and lipid raft enriched fractions. Rather, the sonication results are in keeping with a greater proportion of multimeric assemblies, fibrils or aggregated species of prions existing in the lipid raft compared to ER/MT marker enriched fractions, with sonication increasing the number of replication-competent prion oligomeric strand ends which are then more efficient at transmission and inducing prion propagation. Recent publications provide credence to this hypothesis $[68,69]$, with direct visualisation of the fragmentation of recombinant $\operatorname{PrP}$ after sonication. However, the current study does not exclude any positive effect that sonication may have had on other cellular components contained within the fraction mileu or interactions between the prion protein and other molecules. In fact another recent publication [70] found that sonication also fragments purified liver RNA, to a size that has previously been shown to stimulate prion conversion in PMCA assays. However the RNA sonication produced optimal (sized) RNA after approximately 8 cycles, whereas our sonication experiment was equivalent to one cycle, giving some support to the plausibility of our former hypothesis. Ongoing studies, including the utilisation of techniques such as the conformation dependent immunoassay (CDI) to measure prions in the fractions [71], and sophisticated size fractionation techniques, will help clarify the exact biophysical nature of the variably efficient prion species in the lipid raft and ER/MT enriched fractions.

The association of prion infectivity with MT and ER has been previously investigated with conflicting results. One study showed that purified mitochondria and mitoplast fractions from scrapie infected hamster brain contained infectivity titres equivalent to those determined for crude brain homogenate, yet mitoplast fractions were not associated with detectable levels of $\operatorname{PrP}$ [72], in keeping with the findings of the present study. These results, which suggested an association of high levels of scrapie infectivity with the inner mitochondrial membrane or mitochondrial matrix, are broadly consistent with the characteristics of MoRK13-inf ER/MT enriched fractions, which co-localised with the mitochondrial membrane marker Bcl-2 [73]. An integral and unique (to mitochondria) lipid component of the inner mitochondrial membrane is cardiolipin, a form of dimeric phosphatidylglycerol [74]. Interestingly, utilizing serial PMCA, researchers have recently been able to produce protease resistant, infectious prions from recombinant PrP mixed with RNA and the synthetic phosphatidylglycerol, POPG (1-palmitoyl-2-oleoylphosphatidylglycerol) [75]. The authors state that the POPG and RNA additives to their PMCA may be mimicking factors which facilitate the conversion process in vivo, which is entirely consistent with the results presented here implicating mitochondrial component enriched fractions as containing highly efficient infectious prions.

Somewhat incongruent with these observations, a much earlier study examined the infectivity of scrapie within membrane fractions and found that brain derived purified mitochondrial fractions were associated with very little infectivity [76]. Nevertheless, similar to our results, Millson and colleagues [76] did find both brain and spleen derived subcellular fractions containing elevated enzyme activities usually associated with the ER and plasma membrane were associated with high scrapie infectivity. Conversely, Alais and colleagues [77] found fractions enriched in the ER marker Bip harboured no infectivity, despite containing moderate levels of $\mathrm{PrP}^{\text {res }}$. This result, whilst presenting another example of discrepancy between $\mathrm{PrP}^{\text {res }}$ levels and infectivity, clearly contrasts with what was observed in the MoRK13-inf fractions, perhaps reflecting the different methods and prion strain-cell model employed.

\section{Conclusions}

Through the use of both in vitro and in vivo transmission studies, we have corroborated previously reported discrepancies between absolute $\operatorname{PrP}^{\text {res }}$ levels and infectivity and provided insight into the basis of this phenomenon. Through subcellular separation of infectivity, our data indicates that a substantial amount of infectivity is contained outside of buoyant lipid raft fractions and importantly showed that the most transmission efficient prions per detectable $\mathrm{PrP}^{\mathrm{res}}$ unit were associated with either ER and/or MT membranes or proteins. We established that the high transmission efficiency shown by the ER/MT containing fractions was not due to the simultaneous separation of a more potent prion strain. As critical co-factor enrichment could not be completely excluded, it remains to be determined whether cellular microenvironments directly but variably contribute to the transmission efficiency of resident prions, or only passively serve as sequestration sites for the different prion species. Overall the current study broadly aligns with the notion that rather than absolute levels of $\operatorname{PrP}^{\text {res }}$, intrinsic prion properties may dictate or be dictated by the ultimate subcellular localisation of infectious prions, with transmission efficiency likely correlating best with optimal prion oligomeric state for template directed conversion. Importantly, through the development and validation of a tractable model, further detailed exploration of these fundamental aspects of prion biology, including assessment of other cell line-prion strain combinations to determine the breadth of applicability of our observations, can be undertaken. 


\section{Methods}

\section{Cell culture}

Rabbit kidney epithelial cells which have no detectable endogenous $\operatorname{PrP}^{\mathrm{C}}$ protein, were stably transfected to overexpress murine $\operatorname{PrP}^{\mathrm{C}}$ (MoRK13) or the empty vector (vecRK13) [78] and mouse hypothalamic GT1-7H cells were maintained as described previously [79], in a humidified incubator at $37^{\circ} \mathrm{C}$ with $5 \% \mathrm{CO}_{2}$.

\section{Subcellular fractionation}

A method of non-toxic/non-detergent cell lysis and subcellular separation was necessary to allow subsequent use of fractions for infecting recipient cells or mice. Also, due to the possible involvement of lipid rafts in prion conversion, a lysis method was chosen in order to maintain lipid raft integrity and buoyancy [35], with minor modifications. Briefly two confluent T175 $\mathrm{cm}^{2}$ flasks (approximately $4 \times 10^{7}$ cells) were washed twice with $20 \mathrm{mls}$ ice cold lysis buffer (20 mM Tris-Cl pH 7.8, $250 \mathrm{mM}$ sucrose, $1 \mu \mathrm{M}$ $\mathrm{CaCl}_{2}, 1 \mu \mathrm{M} \mathrm{MgCl}$ ) and harvested by scraping into a further $20 \mathrm{ml}$ of lysis buffer and pelleting at $700 \times \mathrm{g}$ for 3 minutes. The cell pellet was re-suspended in $500 \mu \mathrm{l}$ cold lysis buffer. Cells were lysed on ice, by passing the cell suspension through a $22 \mathrm{~g}$ needle exactly twenty times, and the crude lysate was centrifuged at $1000 \times \mathrm{g}, 10$ minutes at $4^{\circ} \mathrm{C}$. The post-nuclear supernatant was retained on ice and the extraction repeated on the pellet. The lysate was then assayed for total protein content by performing a bicinchoninic acid (BCA) assay (Pierce, Thermo Scientific, Scoresby, VIC, AUS) as per the manufacturer's instructions, and adjusted with lysis buffer to $1.8 \mathrm{mg} / \mathrm{ml}$. The Nycodenz (HistoDenz ${ }^{\mathrm{TM}}$, Sigma-Aldrich, Castle Hill, NSW, AUS) density gradient fractionation method was adapted from a published protocol [80], to suit a Beckman Optima Max-E Benchtop Ultracentrifuge and MLS-50 rotor. Nycodenz solutions were prepared in TNE (25 mM Tris-Cl pH 7.5, $150 \mathrm{mM} \mathrm{NaCl}, 5 \mathrm{mM}$ EDTA) and an 8$35 \%$ linear step Nycodenz gradient was poured (400 $\mu \mathrm{l}$ of each of $8 \%, 12 \%, 15 \%, 18 \%, 20 \%, 22.5 \%$ and $25 \%$ ) with 1.1 $\mathrm{ml}$ of a $35 \%$ Nycodenz cushion consisting of equal parts ice cold $70 \%$ Nycodenz and cell lysate (1 mg total protein) pipetted to the bottom of the gradient. In some cases, an 'empty Nycodenz' gradient was poured, whereby the $35 \%$ Nycodenz/lysate cushion mixture was substituted for $35 \%$ Nycodenz alone. Nycodenz gradients were centrifuged at $200,000 \times \mathrm{g}$ (average) for 342 minutes at $4^{\circ} \mathrm{C}$. Following centrifugation, 10 equal volume fractions of $390 \mu \mathrm{l}$ were collected and stored at $-80^{\circ} \mathrm{C}$ or kept on ice for immediate use.

\section{Prion strain and cell infections}

The M1000 prion strain used in this study was derived from a well characterised stock of pooled mouse brain homogenate [81]. Recipient MoRK13 or GT1-7H cells were infected using an overlay technique as described previously [79]. For comparisons of cell lysate and brain homogenate M1000 infectivity, cell lysates were prepared by harvesting and lysing in sterile phosphate buffered saline (PBS; Invitrogen, Mulgrave, VIC, AUS) by three cycles of freezing $\left(10\right.$ minutes at $\left.-80^{\circ} \mathrm{C}\right)$ and thawing $\left(3\right.$ minutes at $\left.37^{\circ} \mathrm{C}\right)$, and centrifugation at $1000 \times \mathrm{g}$ for 3 minutes at $4^{\circ} \mathrm{C}$ to obtain a post-nuclear supernatant. The total protein content of the PBS supernatant and M1000 brain homogenate were determined by BCA assay, and the lysates and homogenate were balanced to the same protein concentration with PBS. Following this $100 \mu \mathrm{l}$ of lysate or homogenate was mixed with $400 \mu \mathrm{l}$ of complete medium and this was used to infect recipient cells. For fraction infections $100 \mu \mathrm{l}$ fraction ('neat') or, where indicated, fraction which had been serially diluted in medium, was mixed with $400 \mu \mathrm{l}$ complete medium, and used to infect recipient MoRK13 cells. For 'spiking' experiments, M1000 brain homogenate was diluted in $400 \mu \mathrm{l}$ media and mixed with $100 \mu \mathrm{l}$ MoRK13 or vecRK13 fraction (or as a control the lysis buffer used to prepare cells prior to fractionation) to give a final concentration of $0.05 \%, 0.025 \%$ and $0.0125 \%$ M1000, prior to being used to infect recipient MoRK13 cells.

\section{Subcellular fraction pre-treatments}

For PK digestion, $100 \mu \mathrm{l}$ of a fraction was treated with a final concentration of $1 \mu \mathrm{g} / \mathrm{ml} \mathrm{PK}$ for 8 hours at $37^{\circ} \mathrm{C}$, conditions found to reduce $\operatorname{PrP}^{\mathrm{C}}$ by approximately $80 \%$ when tested on control fractions (data not shown). For sonication pre-treatment, $100 \mu \mathrm{l}$ of a fraction in a $1.5 \mathrm{ml}$ microfuge tube was subjected to 60 seconds at amplitude 70 in a $\$ 4000$ sonicator (Misonix, Farmingdale, NY, USA) with microplate horn adapter in $300 \mathrm{~mL}$ water maintained at $37^{\circ} \mathrm{C}$. The PK digested or sonicated fractions (and untreated controls) were mixed with $400 \mu \mathrm{l}$ of complete medium and used for in vitro infections as described above.

\section{Immunoblotting}

For determination of subcellular localisation of PrP and other proteins, fractions were mixed with $4 \mathrm{X}$ sample buffer and subject to PAGE (using either $4-20 \%$ or $10-20 \%$ Tris-glycine SDS or 4-12\% Bis-tris NuPAGE pre-cast gels (Invitrogen), depending on the size of the proteins to be detected, and then transferred to PVDF membrane for western blotting of PrP as described previously [79] and organelle marker proteins using antibody dilutions as outlined in the manufacturer's instructions (BD Pharmingen $^{\mathrm{TM}}$ Organelle Sampler Kit, BD Biosciences, North Ryde, NSW, AUS). For detection of the ganglioside $\mathrm{GM}_{1}$ (lipid raft marker), $3 \mu \mathrm{l}$ of each fraction was spotted onto nitrocellulose membrane, and allowed to dry for 20 minutes at 
$37^{\circ} \mathrm{C}$. The membrane was blocked for a minimum of 1 hour in 5\% skim milk powder in PBS containing 0.05\% (v/ v) Tween-20 (PBST) and then incubated in 1:100,000 cholera toxin B subunit (CTB)-horseradish peroxidise (HRP) conjugate (Sigma, stock concentration $0.45 \mathrm{mg} / \mathrm{ml} \mathrm{CTB}$ and $1 \mathrm{mg} / \mathrm{ml} \mathrm{HRP} \mathrm{in} \mathrm{H}_{2} \mathrm{O}$ ) solution in block for 1.5 hours at room temperature prior to chemiluminescent detection (ECL Plus, GE Healthcare, Rydalmere, NSW, AUS). For $\mathrm{PrP}^{\text {res }}$ detection, fractions, cell lysates or brain homogenate were digested with a final concentration of $50 \mu \mathrm{g} / \mathrm{ml} \mathrm{PK}$, 1 hour at $37^{\circ} \mathrm{C}$ before SDS-PAGE and western blotting. Dot blots of fractions were also carried out for $\mathrm{PrP}^{\text {res }}$ detection, whereby $5 \mu \mathrm{l}$ of fraction was spotted onto nitrocellulose membrane, which was dried 30-60 minutes at $37^{\circ} \mathrm{C}$ and then treated in exactly the same manner as the cell blot assay nitrocellulose membrane. Cell blots for the detection of $\mathrm{PrP}^{\mathrm{res}}$ in recipient cells, at four passages (P4) post-infection were carried out as described previously [79]. All immunoblotting (western blots and cell blots) for PrP species used the monoclonal antibody ICSM18, (DGen, London, UK). All chemiluminescent images were captured by a Fujifilm LAS-3000 (Berthold Australia, Bundoora, VIC, AUS).

\section{In vivo prion transmissions}

All animal experiments were carried out in strict accordance with the 'Australian Code of Practice for the Care and Use of Animals for Scientific Purposes (NHMRC)', with approval from the University of Melbourne Animal Ethics Committee (AEC \#04154). Tga20 PrP $\mathrm{P}^{\mathrm{C}}$ overexpressing mice [82] were anesthetised using methoxyfluorane and inoculated intracerebrally with $30 \mu \mathrm{l}$ of 0.01\% M1000 brain homogenate diluted in PBS or the appropriate fractions as indicated, or with $30 \mu \mathrm{l}$ of 'neat' fraction or whole cell PBS lysate. Mice were provided food and water ad libitum and housed following routine animal husbandry practices. Mice were examined daily for symptoms of prion disease. Once mice developed persisting features of advanced prion disease, including impaired righting reflexes, hunched posture and hind limb paresis, they were culled by cervical dislocation under anaesthesia and the number of days post-inoculation was recorded. Brains were removed and sagittally hemi-sectioned, with half the brain fixed and stained to allow scoring of vacuolation, astrocytic gliosis and PrP deposition as described previously [40], and the other half made to $10 \%(\mathrm{w} / \mathrm{v})$ homogenates in PBS, with homogenates stored at $-80^{\circ} \mathrm{C}$ until required. Neuropathological scoring was performed on two separate occasions, blinded as to the inoculum group, to provide a semiquantitative comparison of lesion profiles between the groups of animals. Stained sections were visualised using a Zeiss Axioskop 50 microscope with images captured using a Zeiss AxioCam HRC camera (Carl Zeiss, North Ryde, NSW, AUS).

\section{Densitometry and statistical analysis}

All densitometric analyses used the public domain ImageJ software (National Institutes of Health, USA). For determining relative levels of $\mathrm{PrP}^{\text {res }}$ in fractions, each fraction $\mathrm{PrP}^{\mathrm{res}}$ dot blot signal intensity was measured, with the sum of the 10 individual $\mathrm{PrP}^{\text {res }}$ levels providing the 'total $\mathrm{PrP}^{\mathrm{res}}$; each individual fraction was expressed as a percentage of the total $\mathrm{PrP}^{\mathrm{res}}$. For determining relative levels of infectivity contained within MoRK13-infectious fractions, $\mathrm{PrP}^{\mathrm{res}}$ produced by MoRK13 cells exposed to each 'neat' fraction was measured at passage 4 (P4) post-exposure by cell blot signal intensity, with the sum of the 10 individual $\mathrm{PrP}^{\mathrm{res}}$ levels providing 'total $\mathrm{PrP}^{\mathrm{res}}$. Once again, each individual fraction was expressed as a percentage of the calculated total $\operatorname{PrP}^{\text {res }}$. All statistical analyses were performed in GraphPad Prism 4, with one way ANOVA and Tukey's multiple comparisons or two way ANOVA and Bonferonni post-tests used as indicated, unless stated otherwise.

\section{Additional material}

Additional file 1: Figure S1. Disparity in PrPres levels and relative infectivity in the MoRK13-inf cell prion infection model. Representative western blot (A) and quantification (B) of PrPres levels in MoRK13-inf whole cell lysates relative to M1000 brain homogenate $(n=3)$. Samples were balanced for total protein; $5 \mu \mathrm{g}$ total protein was resolved in untreated (-) lanes; $50 \mu \mathrm{g}$ total protein was proteinase K (PK) digested (+) and resolved on 4-12\% Bis-tris NuPAGE gels. Very long exposures were required to visualise the $\mathrm{PrP}^{\text {res }}$ within cell lysates, hence the loss of distinction between M1000 PrPres glycoforms. Representative cell blot (C) and quantification (D) of PrPres produced by recipient MoRK13 cells infected with equivalent total protein amounts of M1000 or MoRK13-inf cell lysate $(n=3)$. Note infections utilised the corresponding lysate/ homogenate shown in (A). NBH = Balb/c normal brain homogenate. Statistical analysis by one way ANOVA; ${ }^{* *} p<0.001$, $^{* *} p<0.01$.

Additional file 2: Figure S2. Localisation of PrP, organelle and membrane markers in Nycodenz density gradient fractions of alternative cell lines. Representative immunoblots of subcellular fractions obtained from vector only transfected RK13 cells (vecRK13), GT1-7H and (M1000 infected) GT1-7Hinf, subject to SDS-PAGE and western blotting as described in the methods. CTB dot blot - $3 \mu$ l of fraction was dried onto nitrocellulose membrane, and blotted as described in the methods. $L R=$ lipid raft; $E R=$ endoplasmic reticulum; $M T$ = mitochondria; $E E$ = early endosome; $C T B=$ cholera toxin subunit $\mathrm{B}$; Flot1 = Flotillin 1; $\mathrm{BCl}-2=$ anti-apoptotic $\mathrm{MT}$ marker protein; Bip = ER lumen chaperone protein; EEA1 = EE antigen 1.

Additional file 3: Figure S3. Localisation of PrP isoforms, organelle and membrane markers in Nycodenz density gradient fractions of M1000 brain. Representative immunoblots of subcellular fractions obtained from terminal M1000 brain. Brains were homogenised in a comparative way to the detergent-free cell lysis described in the methods, and then subject to Nycodenz gradient fractionation. Briefly, whole brains (snap frozen in liquid $\mathrm{N}_{2}$ and stored at $-80^{\circ} \mathrm{C}$ ) were homogenised in TNE buffer by passing the tissue through an $18 \mathrm{~g}$ and then a $20 \mathrm{~g}$ needle until an even homogenate was formed, followed by exactly 20 passes through a $22 \mathrm{~g}$ needle. The homogenate was centrifuged at $1000 \times g, 10$ minutes at $4^{\circ}$ $C$, the post-nuclear supernatant was retained on ice and the extraction repeated on the pellet. The supernatant was then subject to Nycodenz gradient floatation, fractions were collected and analysed by SDS-PAGE 
and western blotting as described. PrPres and CTB dot blots - $3 \mu$ l of fraction was dried onto nitrocellulose membrane, and blotted as described in the methods. CTB = cholera toxin subunit $B$; Flot1 = Flotillin 1; $\mathrm{BCl}-2=$ anti-apoptotic mitochondrial marker protein; $\mathrm{Bip}=\mathrm{ER}$ lumen chaperone protein.

Additional file 4: Figure S4. Illustration of the reduction of infectious titre in a 35-day extension of incubation period in Tga20 mice. Regression analysis (modelled on the results of an incubation time interval assay based on quantal end-point dose titration of M1000 brain homogenate in Tga20 mice) was used to plot the relationship between incubation period and titre (V.A. Lawson, unpublished data). The red and blue lines highlight an incubation period of 35 days and the corresponding titres.

Additional file 5: Figure S5. Assessment of neuropathology in the brains of Tga20 mice inoculated with $0.01 \%(w / v)$ M1000 brain homogenate, MoRK13 and MoRK13-inf whole cell lysates and selected MoRK13-inf fractions. Representative photomicrographs demonstrating the degree of (A) vacuolation in hematoxylin and eosin-stained $(\mathrm{H} \& \mathrm{E})$ sections, (B) astrocytic gliosis in glial fibrillary acidic protein (GFAP) stained sections, and (C) PrP plaque deposition in ICSM18 stained sections of various brain regions as indicated. Magnification $=50 \times$ for all sections/stains except $\mathrm{H}$ \& E stained hippocampus and occipital pole, where magnification $=100 \times$.

Additional file 6: Figure S6. PrPres profiles in Tga20 mice inoculated with $0.01 \%(\mathrm{w} / \mathrm{V}) \mathrm{M} 1000$ brain homogenate, MoRK13-inf and selected MoRK13-inf subcellular fractions. Representative western blot (A) and quantification (B) of Prpres glycoform ratios in terminal mice brains after intracerebral inoculation as indicated. (A) $10 \mu \mathrm{l}$ of PK digested $(100 \mu \mathrm{g} / \mathrm{ml}$ final concentration PK, 1 hour at $37^{\circ} \mathrm{C}$ ) $10 \%(\mathrm{~W} / \mathrm{V}$ in PBS) homogenate was resolved on $12 \%$ Bis-tris NUPAGE and probed with ICSM18 primary antibody and (B) quantified using Image J. $\mathrm{Di}=$ di-glycosylated Prpres, mono = mono-glycosylated PrPres, un = unglycosylated PrPres. Statistical analysis by two-way ANOVA with Bonferroni post-tests; ns = no significant differences; ${ }^{\#}$ M1000 in Balb/c mice was significantly different to all other inocula; $\wedge 0.01 \%$ M1000 in Tga20 mice was significantly different to all other inocula.

Additional file 7: Figure S7. Exogenous cellular co-factors from vecRK13 do not differentially increase the efficiency of M1000 infection in vitro. (A) Cell blot showing PrPres levels produced by recipient MoRK13 cells exposed to M1000 brain homogenate diluted to three different final concentrations (as indicated) with either 1:4 lysis buffer (LB):medium or 1:4 vecRK13 fraction:medium mix. (B) Quantification of PrPres produced by MoRK13 cells exposed to M1000 brain homogenate diluted in subcellular fraction relative to the equivalent $\%$ M1000 brain homogenate diluted in lysis buffer; for quantification purposes the three different \% M1000 spikes into the same vecRK13 fractionated lysate were considered a triplicate of the same experiment, with the error bars representing this intra-experiment variation, and analysis of this variation (one way ANOVA) showing no significant differences. Fractions enriched in lipid raft (LR), endoplasmic reticulum (ER), mitochondrial (MT) and early endosome (EE) marker proteins are as marked.

Additional file 8: Figure S8. Lesion profiles from Tga20 mice intracerebrally inoculated with M1000 brain homogenate diluted in PBS and high density Nyocodenz with or without MoRK13 cell lysate content. Lesion profiles generated by quantification of the degree of vacuolation (H\&E), reactive astrocytosis (GFAP) and PrP plaque deposition in each brain region (HI - hippocampus, TH - thalamus, OP - occipital pole, CE cerebellum, $\mathrm{MB}$ - midbrain, $\mathrm{PO}$ - pons). $\mathrm{n}=3$ or 4 for all brain regions except in $0.01 \%$ M1000 diluted in PBS HI PrP plaque deposition, where $\mathrm{n}$ $=2$. Statistical analysis comparing lesion profiles was by two way ANOVA. For astrocytic gliosis and PrP plaque deposition, ${ }^{*} \mathrm{p}<0.05$ comparing M1000 diluted in PBS and Nycodenz fraction \#10 in TH region only. No other significant differences seen.

\section{Abbreviations}

BCA: Bicinchoninic acid; CDI: Conformation dependent immunoassay; CTB: Cholera toxin B subunit; EE: Early endosome; ER: Endoplasmic reticulum; MT:
Mitochondria; PBS: Phosphate buffered saline; PK: Proteinase K; PMCA: Protein misfolding cyclic amplification; POPG: 1-palmitoyl-2oleoylphosphatidylglycerol; PrP: Prion protein; PrPC: Cellular prion protein; Prpres: Protease resistant prion protein.

\section{Acknowledgements}

The authors thank Professor Charles Weissmann for the gift of the Tga20 transgenic mice, the Animal Housing Facility staff in the Faculty of Medicine, Dentistry and Health Sciences, the University of Melbourne for their assistance with animal husbandry, and Ms Laura Leone for technical assistance with preparation of the mouse brains for neuropathological assessment. This work was funded by an Australian Government National Health and Medical Research Council (NHMRC) Program Grant (\#400202). VL is supported by NHMRC Training Fellowship (\#567123). SJC is supported by NHMRC Practitioner Fellowship (\#400183). VAL is supported by The University of Melbourne CR Roper Fellowship. AFH is supported by an Australian Research Council Future Fellowship (FT10100560).

\section{Author details}

'Department of Pathology, The University of Melbourne, Parkville, VIC 3010, Australia. ${ }^{2}$ Mental Health Research Institute and the Melbourne Brain Centre, The University of Melbourne, Parkville, VIC 3010, Australia. ${ }^{3}$ Department of Biochemistry and Molecular Biology and the Bio21 Molecular Science and Biotechnology Institute, The University of Melbourne, Parkville, VIC 3010, Australia.

\section{Authors' contributions}

VL performed all experiments. VL, CLH and SJC were involved in the acquisition of data. VL, AFH, VAL and SJC contributed to experimental conception and design. VL, CLH, CLM, AFH, VAL and SJC were involved in analysis and interpretation of data and production of this manuscript. All authors read and approved the final manuscript.

\section{Competing interests}

The authors declare that they have no competing interests.

Received: 11 November 2011 Accepted: 26 April 2012 Published: 26 April 2012

\section{References}

1. Prusiner SB: Prions. Proc Natl Acad Sci USA 1998, 95:13363-13383.

2. Pan KM, Baldwin M, Nguyen J, Gasset M, Serban A, Groth D, Mehlhorn I, Huang Z, Fletterick RJ, Cohen FE, et al: Conversion of alpha-helices into beta-sheets features in the formation of the scrapie prion proteins. Proc Natl Acad Sci USA 1993, 90:10962-10966.

3. Caughey BW, Dong A, Bhat KS, Ernst D, Hayes SF, Caughey WS: Secondary structure analysis of the scrapie-associated protein PrP 27-30 in water by infrared spectroscopy. Biochemistry 1991, 30:7672-7680.

4. Prusiner SB, McKinley MP, Bowman KA, Bolton DC, Bendheim PE, Groth DF, Glenner GG: Scrapie prions aggregate to form amyloid-like birefringent rods. Cell 1983, 35:349-358.

5. Prusiner SB, Bolton DC, Groth DF, Bowman KA, Cochran SP, McKinley MP: Further purification and characterization of scrapie prions. Biochemistry 1982, 21:6942-6950.

6. McKinley MP, Bolton DC, Prusiner SB: A protease-resistant protein is a structural component of the scrapie prion. Cell 1983, 35:57-62.

7. Collins SJ, Lewis V, Brazier MW, Hill AF, Lawson VA, Klug GM, Masters CL: Extended period of asymptomatic prion disease after low dose inoculation: assessment of detection methods and implications for infection control. Neurobiol Dis 2005, 20:336-346.

8. Balkema-Buschmann A, Eiden M, Hoffmann C, Kaatz M, Ziegler U, Keller M, Groschup MH: BSE infectivity in the absence of detectable PrPSC accumulation in the tongue and nasal mucosa of terminally diseased cattle. J Gen Virol 2010, doi:10.1099/vir.0.025387-0.

9. Tixador P, Herzog L, Reine F, Jaumain E, Chapuis J, Le Dur A, Laude H, Beringue $\mathrm{V}$ : The physical relationship between infectivity and prion protein aggregates is strain-dependent. PLoS Pathog 2010, 6: e1000859.

10. Hill AF, Joiner S, Linehan J, Desbruslais M, Lantos PL, Collinge J: Speciesbarrier-independent prion replication in apparently resistant species. Proc Natl Acad Sci USA 2000, 97:10248-10253. 
11. Manuelidis L, Fritch W, Xi YG: Evolution of a strain of CJD that induces BSE-like plaques. Science 1997, 277:94-98.

12. Lasmezas Cl, Deslys JP, Robain O, Jaegly A, Beringue V, Peyrin JM, Fournier JG, Hauw JJ, Rossier J, Dormont D: Transmission of the BSE agent to mice in the absence of detectable abnormal prion protein. Science 1997, 275:402-405.

13. Czub M, Braig HR, Diringer H: Pathogenesis of scrapie: study of the temporal development of clinical symptoms, of infectivity titres and scrapie-associated fibrils in brains of hamsters infected intraperitoneally. J Gen Virol 1986, 67(Pt 9):2005-2009.

14. Barron RM, Campbell SL, King D, Bellon A, Chapman KE, Williamson RA, Manson JC: High titers of transmissible spongiform encephalopathy infectivity associated with extremely low levels of PrPSc in vivo. J Biol Chem 2007, 282:35878-35886.

15. Castilla J, Saa P, Hetz C, Soto C: In vitro generation of infectious scrapie prions. Cell 2005, 121:195-206.

16. Lewis $\mathrm{V}$, Hooper NM: The role of lipid rafts in prion protein biology. Front Biosci 2011, 16:151-168

17. Kaneko K, Zulianello L, Scott M, Cooper CM, Wallace AC, James TL, Cohen FE, Prusiner SB: Evidence for protein $\times$ binding to a discontinuous epitope on the cellular prion protein during scrapie prion propagation. Proc Natl Acad Sci USA 1997, 94:10069-10074.

18. Telling GC, Scott M, Mastrianni J, Gabizon R, Torchia M, Cohen FE, DeArmond SJ, Prusiner SB: Prion propagation in mice expressing human and chimeric PrP transgenes implicates the interaction of cellular PrP with another protein. Cell 1995, 83:79-90.

19. Yehiely F, Bamborough P, Da Costa M, Perry BJ, Thinakaran G, Cohen FE, Carlson GA, Prusiner SB: Identification of candidate proteins binding to prion protein. Neurobiol Dis 1997, 3:339-355.

20. Gomes MP, Millen TA, Ferreira PS, Cunha ESNL, Vieira TC, Almeida MS, Silva $J \mathrm{~L}$, Cordeiro $Y$ : Prion protein complexed to N2a cellular RNAs through its $\mathrm{N}$-terminal domain forms aggregates and is toxic to murine neuroblastoma cells. J Biol Chem 2008, 283:19616-19625

21. Deleault NR, Lucassen RW, Supattapone S: RNA molecules stimulate prion protein conversion. Nature 2003, 425:717-720.

22. Adler V, Zeiler B, Kryukov V, Kascsak R, Rubenstein R, Grossman A: Small, highly structured RNAs participate in the conversion of human recombinant $\operatorname{PrP}($ Sen) to $\operatorname{PrP}($ Res) in vitro. J Mol Biol 2003, 332:47-57.

23. Geoghegan JC, Valdes PA, Orem NR, Deleault NR, Williamson RA, Harris BT, Supattapone S: Selective incorporation of polyanionic molecules into hamster prions. J Biol Chem 2007, 282:36341-36353.

24. Liu M, Yu S, Yang J, Yin X, Zhao D: RNA and $\mathrm{CuCl} 2$ induced conformational changes of the recombinant ovine prion protein. $\mathrm{Mol}$ Cell Biochem 2007, 294:197-203.

25. Schonberger O, Horonchik L, Gabizon R, Papy-Garcia D, Barritault D, Taraboulos A: Novel heparan mimetics potently inhibit the scrapie prion protein and its endocytosis. Biochem Biophys Res Commun 2003, 312:473-479.

26. Ben-Zaken O, Tzaban S, Tal Y, Horonchik L, Esko JD, Vlodavsky I, Taraboulos A: Cellular heparan sulfate participates in the metabolism of prions. J Biol Chem 2003, 278:40041-40049.

27. Mayer-Sonnenfeld T, Zeigler M, Halimi M, Dayan Y, Herzog C, Lasmezas Cl, Gabizon R: The metabolism of glycosaminoglycans is impaired in prion diseases. Neurobiol Dis 2005, 20:738-743.

28. Taylor DR, Whitehouse IJ, Hooper NM: Glypican-1 mediates both prion protein lipid raft association and disease isoform formation. PLOS Pathog 2009, 5:e1000666.

29. Lawson VA, Lumicisi B, Welton J, Machalek D, Gouramanis K, Klemm HM, Stewart JD, Masters CL, Hoke DE, Collins SJ, Hill AF: Glycosaminoglycan sulphation affects the seeded misfolding of a mutant prion protein. PLOS One 2010, 5:e12351.

30. Silveira JR, Raymond GJ, Hughson AG, Race RE, Sim VL, Hayes SF, Caughey B: The most infectious prion protein particles. Nature 2005 437:257-261

31. Weber P, Reznicek L, Mitteregger G, Kretzschmar H, Giese A: Differential effects of prion particle size on infectivity in vivo and in vitro. Biochem Biophys Res Commun 2008, 369:924-928.

32. Borchelt DR, Scott M, Taraboulos A, Stahl N, Prusiner SB: Scrapie and cellular prion proteins differ in their kinetics of synthesis and topology in cultured cells. J Cell Biol 1990, 110:743-752.
33. Shyng SL, Huber MT, Harris DA: A prion protein cycles between the cell surface and an endocytic compartment in cultured neuroblastoma cells. J Biol Chem 1993, 268:15922-15928.

34. Gilch S, Winklhofer KF, Groschup MH, Nunziante M, Lucassen $R$ Spielhaupter C, Muranyi W, Riesner D, Tatzelt J, Schätzl HM: Intracellular rerouting of prion protein prevents propagation of $\mathrm{PrP}^{\mathrm{Sc}}$ and delays onset of prion disease. EMBO J 2001, 20:3957-3966.

35. Macdonald $J$, Pike $L J$ : A simplified method for the preparation of detergent-free lipid rafts. J Lipid Res 2005, 46:1061-1067.

36. Naslavsky N, Shmeeda H, Friedlander G, Yanai A, Futerman AH, Barenholz Y, Taraboulos A: Sphingolipid depletion increases formation of the scrapie prion protein in neuroblastoma cells infected with prions. J Biol Chem 1999, 274:20763-20771

37. Liberski PP, Ironside JW: An outline of the neuropathology of transmissible spongiform encephalopathies (prion diseases). Folia Neuropathol 2004, 42.

38. Bruce ME, Boyle A, Cousens S, McConnell I, Foster J, Goldmann W, Fraser H: Strain characterization of natural sheep scrapie and comparison with BSE. J Gen Virol 2002, 83:695-704.

39. Bruce ME, McConnell I, Fraser H, Dickinson AG: The disease characteristics of different strains of scrapie in Sinc congenic mouse lines: implications for the nature of the agent and host control of pathogenesis. J Gen Virol 1991, 72(Pt 3):595-603.

40. Brazier MW, Lewis V, Ciccotosto GD, Klug GM, Lawson VA, Cappai R, Ironside JW, Masters CL, Hill AF, White AR, Collins S: Correlative studies support lipid peroxidation is linked to $\operatorname{PrP}($ res) propagation as an early primary pathogenic event in prion disease. Brain Res Bull 2006, 68:346-354.

41. Lawson VA, Vella LJ, Stewart JD, Sharples RA, Klemm H, Machalek DM, Masters CL, Cappai R, Collins SJ, Hill AF: Mouse-adapted sporadic human Creutzfeldt-Jakob disease prions propagate in cell culture. Int J Biochem Cell Biol 2008, 40:2793-2801.

42. Bessen RA, Marsh RF: Distinct PrP properties suggest the molecular basis of strain variation in transmissible mink encephalopathy. J Virol 1994, 68:7859-7868.

43. Somerville RA, Chong A, Mulqueen OU, Birkett CR, Wood SC, Hope J: Biochemical typing of scrapie strains. Nature 1997, 386:564.

44. Caughey B, Raymond GJ, Bessen RA: Strain-dependent differences in betasheet conformations of abnormal prion protein. J Biol Chem 1998, 273:32230-32235.

45. Parchi P, Castellani R, Capellari S, Ghetti B, Young K, Chen SG, Farlow M, Dickson DW, Sima AA, Trojanowski JQ, et al: Molecular basis of phenotypic variability in sporadic Creutzfeldt-Jakob disease. Ann Neurol 1996, 39:767-778.

46. Collinge J, Sidle KC, Meads J, Ironside J, Hill AF: Molecular analysis of prion strain variation and the aetiology of 'new variant' CJD. Nature 1996, 383:685-690.

47. Tzaban S, Friedlander G, Schonberger O, Horonchik L, Yedidia Y, Shaked G, Gabizon R, Taraboulos A: Protease-sensitive scrapie prion protein in aggregates of heterogeneous sizes. Biochemistry 2002, 41:12868-12875.

48. Thackray AM, Hopkins L, Bujdoso R: Proteinase K-sensitive diseaseassociated ovine prion protein revealed by conformation-dependent immunoassay. Biochem J 2007, 401:475-483.

49. Pastrana MA, Sajnani G, Onisko B, Castilla J, Morales R, Soto C, Requena JR Isolation and characterization of a proteinase K-sensitive PrPSc fraction. Biochemistry 2006, 45:15710-15717.

50. Gambetti P, Dong Z, Yuan J, Xiao X, Zheng M, Alshekhlee A, Castellani R, Cohen M, Barria MA, Gonzalez-Romero D, et al: A novel human disease with abnormal prion protein sensitive to protease. Ann Neurol 2008, 63:697-708.

51. Colby DW, Wain R, Baskakov IV, Legname G, Palmer CG, Nguyen HO, Lemus A, Cohen FE, DeArmond SJ, Prusiner SB: Protease-sensitive synthetic prions. PLoS Pathog 2010, 6:e1000736.

52. Stathopulos PB, Scholz GA, Hwang YM, Rumfeldt JA, Lepock JR, Meiering EM: Sonication of proteins causes formation of aggregates that resemble amyloid. Protein Sci 2004, 13:3017-3027.

53. Piening N, Weber $\mathrm{P}$, Giese A, Kretzschmar $\mathrm{H}$ : Breakage of PrP aggregates is essential for efficient autocatalytic propagation of misfolded prion protein. Biochem Biophys Res Commun 2005, 326:339-343. 
54. Deleault NR, Harris BT, Rees JR, Supattapone S: Formation of native prions from minimal components in vitro. Proc Natl Acad Sci USA 2007, 104:9741-9746.

55. Lewis V, Hill AF, Klug GM, Boyd A, Masters CL, Collins SJ: Australian sporadic CJD analysis supports endogenous determinants of molecularclinical profiles. Neurology 2005, 65:113-118.

56. Hill AF, Joiner S, Wadsworth JD, Sidle KC, Bell JE, Budka H, Ironside JW, Collinge J: Molecular classification of sporadic Creutzfeldt-Jakob disease. Brain 2003, 126:1333-1346.

57. Biacabe AG, Laplanche $J \mathrm{~L}$, Ryder $\mathrm{S}$, Baron T: Distinct molecular phenotypes in bovine prion diseases. EMBO reports 2004, 5:110-115.

58. Benestad SL, Sarradin P, Thu B, Schonheit J, Tranulis MA, Bratberg B: Cases of scrapie with unusual features in Norway and designation of a new type, Nor98. Vet Rec 2003, 153:202-208.

59. Arsac JN, Biacabe AG, Nicollo J, Bencsik A, Baron T: Biochemical identification of bovine spongiform encephalopathies in cattle. Acta neuropathologica 2007, 114:509-516.

60. Casalone C, Zanusso G, Acutis P, Ferrari S, Capucci L, Tagliavini F, Monaco S, Caramelli M: Identification of a second bovine amyloidotic spongiform encephalopathy: molecular similarities with sporadic Creutzfeldt-Jakob disease. Proc Natl Acad Sci USA 2004, 101:3065-3070.

61. DeMarco ML, Daggett $\mathrm{V}$ : Local environmental effects on the structure of the prion protein. C R Biol 2005, 328:847-862.

62. Kimberlin $\mathrm{RH}$, Walker CA: Evidence that the transmission of one source of scrapie agent to hamsters involves separation of agent strains from a mixture. J Gen Virol 1978, 39:487-496.

63. Puoti G, Giaccone G, Rossi G, Canciani B, Bugiani O, Tagliavini F: Sporadic Creutzfeldt-Jakob disease: co-occurrence of different types of $\operatorname{PrP}(\mathrm{Sc})$ in the same brain. Neurology 1999, 53:2173-2176.

64. Hirogari $Y$, Kubo M, Kimura KM, Haritani M, Yokoyama T: Two different scrapie prions isolated in Japanese sheep flocks. Microbiol Immunol 2003, 47:871-876.

65. Hecker R, Taraboulos A, Scott M, Pan KM, Yang SL, Torchia M, Jendroska K, DeArmond SJ, Prusiner SB: Replication of distinct scrapie prion isolates is region specific in brains of transgenic mice and hamsters. Genes Dev 1992, 6:1213-1228.

66. Bartz JC, Aiken JM, Bessen RA: Delay in onset of prion disease for the HY strain of transmissible mink encephalopathy as a result of prior peripheral inoculation with the replication-deficient DY strain. J Gen Virol 2004, 85:265-273.

67. Courageot MP, Daude N, Nonno R, Paquet S, Di Bari MA, Le Dur A, Chapuis J, Hill AF, Agrimi U, Laude H, Vilette D: A cell line infectible by prion strains from different species. J Gen Virol 2008, 89:341-347.

68. Gonzalez-Montalban N, Makarava N, Ostapchenko VG, Savtchenk R, Alexeeva I, Rohwer RG, Baskakov IV: Highly efficient protein misfolding cyclic amplification. PLoS Pathog 2011, 7:e1001277.

69. Piro JR, Wang F, Walsh DJ, Rees JR, Ma J, Supattapone S: Seeding specificity and ultrastructural characteristics of infectious recombinant prions. Biochemistry 2011, 50:7111-7116.

70. Gonzalez-Montalban N, Makarava N, Savtchenko R, Baskakov IV: Relationship between Conformational Stability and Amplification Efficiency of Prions. Biochemistry 2011, 50:7933-7940.

71. Safar JG, Scott M, Monaghan J, Deering C, Didorenko S, Vergara J, Ball H, Legname $G$, Leclerc E, Solforosi L, et al: Measuring prions causing bovine spongiform encephalopathy or chronic wasting disease by immunoassays and transgenic mice. Nat Biotechnol 2002, 20:1147-1150.

72. Aiken JM, Williamson JL, Marsh RF: Evidence of mitochondrial involvement in scrapie infection. J Virol 1989, 63:1686-1694.

73. Akao Y, Otsuki Y, Kataoka S, Ito Y, Tsujimoto Y: Multiple subcellular localization of bcl-2: detection in nuclear outer membrane, endoplasmic reticulum membrane, and mitochondrial membranes. Cancer Res 1994, 54:2468-2471.

74. Osman C, Voelker DR, Langer T: Making heads or tails of phospholipids in mitochondria. J Cell Biol 2011, 192:7-16.

75. Wang F, Wang X, Yuan CG, Ma J: Generating a prion with bacterially expressed recombinant prion protein. Science 2010, 327:1132-1135.

76. Millson GC, Hunter GD, Kimberlin RH: An experimental examination of the scrapie agent in cell membrane mixtures. II. The association of scrapie activity with membrane fractions. Comp Pathol 1971, 81:255-265.
77. Alais S, Simoes S, Baas D, Lehmann S, Raposo G, Darlix JL, Leblanc P: Mouse neuroblastoma cells release prion infectivity associated with exosomal vesicles. Biol Cell 2008, 100:603-615.

78. Vella L, Sharples RA, Lawson VA, Masters CL, Cappai R, Hill AF: Packaging of prions into exosomes is associated with a novel pathway of PrP processing. J Pathol 2007, 211:582-590.

79. Lewis V, Hill AF, Haigh CL, Klug GM, Masters CL, Lawson VA, Collins SJ: Increased Proportions of C1 Truncated Prion Protein Protect Against Cellular M1000 Prion Infection. J Neuropathol Exp Neurol 2009, 68:1125-1135.

80. Naslavsky N, Stein R, Yanai A, Friedlander G, Taraboulos A: Characterization of detergent-insoluble complexes containing the cellular prion protein and its scrapie isoform. J Biol Chem 1997, 272:6324-6331.

81. Lawson VA, Stewart JD, Masters CL: Enzymatic detergent treatment protocol that reduces protease-resistant prion protein load and infectivity from surgical-steel monofilaments contaminated with a human-derived prion strain. J Gen Virol 2007, 88:2905-2914.

82. Fischer M, Rulicke T, Raeber A, Sailer A, Moser M, Oesch B, Brandner S, Aguzzi A, Weissmann C: Prion protein (PrP) with amino-proximal deletions restoring susceptibility of PrP knockout mice to scrapie. EMBO J 1996, 15:1255-1264.

doi:10.1186/1750-1326-7-18

Cite this article as: Lewis et al:: Prion subcellular fractionation reveals infectivity spectrum, with a high titre-low PrPres level disparity. Molecular Neurodegeneration 2012 7:18.

\section{Submit your next manuscript to BioMed Central and take full advantage of:}

- Convenient online submission

- Thorough peer review

- No space constraints or color figure charges

- Immediate publication on acceptance

- Inclusion in PubMed, CAS, Scopus and Google Scholar

- Research which is freely available for redistribution

Submit your manuscript at www.biomedcentral.com/submit
C) Biomed Central 